\title{
Trauma in Pregnancy at the Yalgado Ouedraogo Teaching Hospital in Ouagadougou, Burkina Faso: Epidemiological, Clinical, Therapeutic and Prognostic Aspect
}

\author{
Ali Ouédraogo ${ }^{*}$, Mohamed Tall², André Simporé1, Françoise D. Traoré Millogo1, \\ Mariam Savadogo ${ }^{1}$, Blandine Thieba Bonane ${ }^{1}$, Jean Lankoandé1 \\ ${ }^{1}$ Department of Obstetrics and Gynecology, Yalgado Ouedraogo Teaching Hospital in Ouagadougou, \\ Ouagadougou, Burkina Faso \\ ${ }^{2}$ Department of Orthopedics and Traumatology, Yalgado Ouedraogo Teaching Hospital in Ouagadougou, \\ Ouagadougou, Burkina Faso \\ Email: ${ }^{\text {doc aliouedraogo@yahoo.fr }}$
}

Received 20 May 2015; accepted 26 July 2015; published 31 July 2015

Copyright (C) 2015 by authors and Scientific Research Publishing Inc.

This work is licensed under the Creative Commons Attribution International License (CC BY). http://creativecommons.org/licenses/by/4.0/ c. (i) Open Access

\section{Abstract}

Objective: To study the epidemiological, clinical, therapeutic and prognostic aspects of trauma in pregnancy at the Yalgado Ouedraogo teaching hospital in Ouagadougou. Patients and Methods: A descriptive retrospective study was done over a period of three years from $1^{\text {st }}$ January 2010 to $31{ }^{\text {st }}$ December 2012. We included in our sample, all pregnant women admitted for trauma in pregnancy and eligible in three clinics: obstetrics/gynecology, orthopedics, general and visceral surgery. Anonymity and confidentiality of collected data were respected. Results: We recorded 224 emergency consultations for trauma in pregnancy out of 26,735 obstetric and gynecological consultations which gave a frequency of $0.8 \%$. The mean age of our patients was $25.9 \pm 5$ years and mean parity was 1 . Housewives accounted for $50 \%$ of patients and referrals were the mode of admission in $74.6 \%$ of cases. The causes of injury were dominated by road traffic accidents in $82.6 \%$ of cases, falls in $9.8 \%$ and assault in $7.6 \%$. The mean gestational age of onset of trauma was $26.3 \pm$ 7 weeks amenorrhea. The management was multidisciplinary with a medical component in $99.1 \%$ of cases, obstetric component in $13 \%$ of cases, a visceral surgery component in $6.7 \%$ of cases and an orthopedic component in $4.2 \%$ case. Multiple traumas were found in 4 patients. The fetal prognosis showed in the $1^{\text {st }}$ trimester 3 cases of abortion in the $2^{\text {nd }}$ trimester 5 cases of intrauterine fetal death and in the $3^{\text {rd }}$ trimester 10 cases of preterm labor. Conclusion: Traumas during preg${ }^{*}$ Corresponding author.

How to cite this paper: Ouédraogo, A., Tall, M., Simporé, A., Millogo, F.D.T., Savadogo, M., Bonane, B.T. and Lankoandé, J. (2015) Trauma in Pregnancy at the Yalgado Ouedraogo Teaching Hospital in Ouagadougou, Burkina Faso: Epidemiological, Clinical, Therapeutic and Prognostic Aspect. Open Journal of Obstetrics and Gynecology, 5, 436-442. 
nancy are beyond emergencies within multiple causes and requiring a multidisci- plinary management. Seen the limited means of support, establishment of a national strategy to prevent trauma in pregnancy will improve the prognosis for mother and child.

\section{Keywords}

\section{Trauma in Pregnancy, Maternal, Fetal, Prognosis, Ouagadougou}

\section{Introduction}

Trauma complicates up to 7\% of all pregnancies. It's the leading cause of death none related to pregnancy [1] [2]. The consequence of these injuries varies according to the term of gestation and the mechanism of occurrence [3].

In Burkina Faso, we noticed more and more increase in number of vehicles and motorcycles. The management of a pregnant woman victim of trauma is delicate and must be multidisciplinary, including obstetricians, intensive care specialists, surgeons and pediatricians [2] [4]. In the absence of previous studies on trauma during pregnancy in Burkina Faso, we propose to describe the epidemiological, clinical, prognostic and therapeutic pattern of these injuries during pregnancy at the Yalgado Ouedraogo Teaching Hospital in Ouagadougou, Burkina Faso.

\section{Patients and Methods}

A descriptive retrospective study was done over a period of three years from $1^{\text {st }}$ January 2010 to $31^{\text {st }}$ December 2012. The study was conducted within the departments of obstetrics and gynecology, orthopedics and general and digestive surgery of Yalgado Ouedraogo Teaching Hospital (CHU-YO), referral hospital of the third level of the health pyramid.

In our study, were included all pregnant women outpatient and hospitalized cases, admitted for trauma in pregnancy during the study period in the three sites. The study variables included socio demographic characteristics, type of trauma, clinical and laboratory data, therapeutic and prognostic data. A structured questionnaire was used to collect data. Data were collected from clinical records, admission records and operative reports records at the obstetrics gynecology, orthopedics and general surgery. A flood occurred on $1^{\text {st }}$ September 2011 has resulted in the physical destruction of clinical records. This justified some missing data.

The data were entered and analyzed on a personal computer by Epi data 3.1 and SPSS (Statistical Package for Social Science). Descriptive statistics for constant variables were defined as mean \pm standard deviation, minimum and maximum values, and categorical variables were defined as number and percent.

Anonymity and confidentiality of collected data were respected.

\section{Results}

\subsection{Frequency}

During the study period, we recorded 224 admissions for trauma in pregnancy for a total of 26,735 admissions representing a frequency of $0.8 \%$. The frequency was $0.9(72 / 8264)$ in 2010, 0.9 (76/8708) in 2011 and 0.8 (76/9763) in 2012.

\subsection{Socio Demographic Characteristics}

\section{- Age and parity}

The mean age of our patients was $25.9 \pm 5$ years with a range of 17 to 42 years. The age group of 20 - 24 years accounted for $35.3 \%$ of cases. The average parity was 1 with a range of 0 to 8 .

\section{- Professional and marital status socio}

Housewives accounted for $50 \%$ of the sample, students $18.3 \%$, employee with income $13.4 \%$, the informal sector $10.3 \%$, seamstresses and hairdressers $8 \%$. Married women accounted for $62 \%$ of our patients, those living with a partner $25 \%$ and singles $13 \%$.

\section{- Living area}

Among our patients, 93.3\% (209 cases) were living in urban areas and 6.7\% in rural areas. 


\subsection{Clinical Pattern}

\section{- Mode of admission}

Patients were brought in by ambulance in $74.6 \%$ cases, referred in $11.6 \%$, and reported themselves in $13.8 \%$ of cases.

\section{- Reason for admission}

The distribution of patients according to the reason for admission is presented in Table 1. The trauma has led to initial loss of consciousness in 25 cases, representing $11.2 \%$.

\section{- Gestational age}

The mean gestational age at the onset of trauma was $26.3 \pm 7.7$ weeks amenorrhea which range of 8 to 40.6 . Trauma occurring in the first trimester accounted for $12.5 \%, 45.1 \%$ for the second trimester and $42.4 \%$ for the third.

\section{- Circumstances of injury}

The distribution of patients according to the circumstances of the injury is shown in Table 2. The assaults and falls accounted for $17.4 \%$ of the circumstances of injury.

\section{- Type of means of transport}

Table 3 shows the distribution of road traffic accidents according to the means of transport involved. Motorcycle was involved in $99.5 \%$ of cases.

\section{- Seasonality of trauma}

The distribution of patients according to the season and the type of trauma is shown in Figure 1. End of year period festivities wasn't associated with increased trauma during pregnancy.

\section{- Type of injury}

The distribution of patients according to the type of injury has been shown in Table 4. Four cases of multiple injuries were noted including 2 by falls from a tree and 2 by road traffic accident.

Table 1. Distribution of patients according to the reason for admission $(n=224)$.

\begin{tabular}{|c|c|c|}
\hline Reason for admission & Number & $\%$ \\
\hline RTA without ILC in pregnancy & 168 & 75 \\
\hline RTA with ILC in pregnancy & 17 & 7.5 \\
\hline Assault without ILC in pregnancy & 14 & 6.3 \\
\hline Fall by herself without ILC in pregnancy & 12 & 5.4 \\
\hline Fall from a tree without ILC in pregnancy & 5 & 2.3 \\
\hline Assault with ILC in pregnancy & 3 & 1.3 \\
\hline Fall from a tree with ILC in pregnancy & 3 & 1.3 \\
\hline Fall by herself with ILC in pregnancy & 2 & 0.9 \\
\hline Total & 224 & 100 \\
\hline
\end{tabular}

RTA: Road traffic accident; ILC: Initial loss of consciousness.

Table 2. Distribution of patients according to the circumstances of traumas $(\mathrm{n}=224)$.

\begin{tabular}{|c|c|c|}
\hline Causes of traumas & Number & $\%$ \\
\hline Road traffic accident & 185 & 82.6 \\
\hline \multicolumn{3}{|l|}{ Fall } \\
\hline - By herself & 14 & 6.2 \\
\hline - From a tree & 8 & 3.6 \\
\hline \multicolumn{3}{|l|}{ Assaults } \\
\hline - Violence among couples & 9 & 4 \\
\hline Other assaults & 8 & 3.6 \\
\hline
\end{tabular}




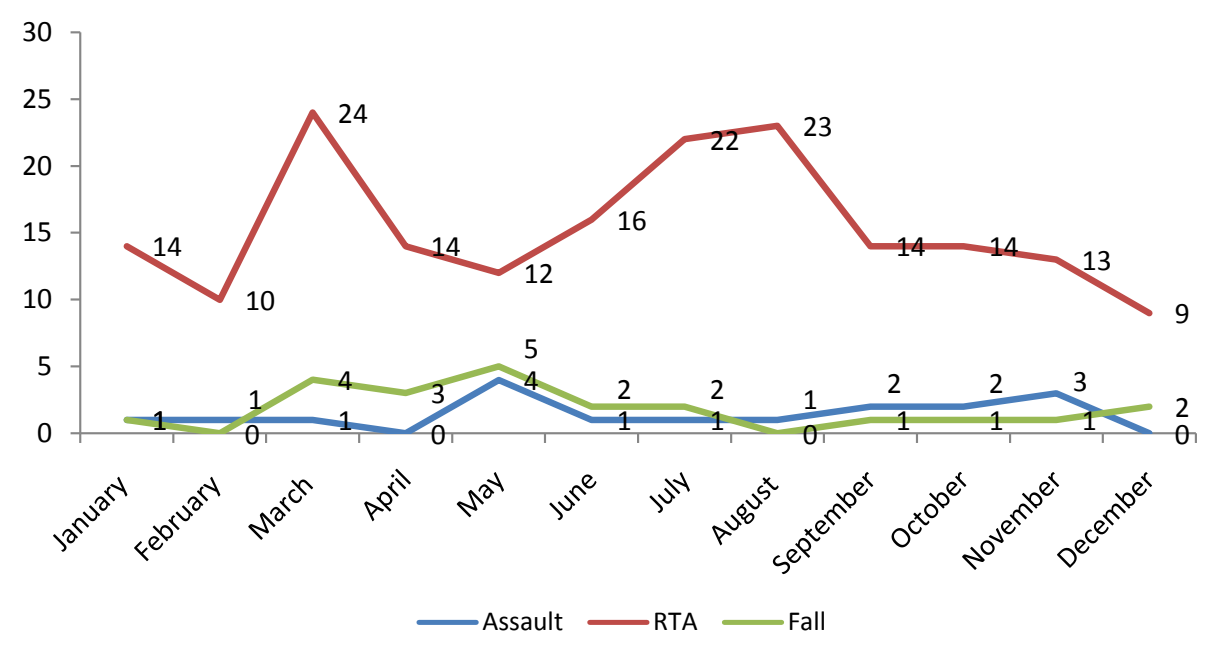

Figure 1. Distribution of patients according to the cause of trauma and months $(n=224)$. (Key: RTA = Road traffic accident).

Table 3. Distribution of road traffic accident according to the mode of transport involved.

\begin{tabular}{ccc}
\hline Mean of transport involved & Number & \% \\
\hline Motorcycle-motorcycle & 119 & 64.3 \\
Motorcycle-car & 32 & 17.4 \\
Motorcycle-pedestrian & 8 & 4.3 \\
Motorcycle only & 25 & 13.5 \\
Car-car & 1 & 0.5 \\
Total & $\mathbf{1 8 5}$ & $\mathbf{1 0 0}$ \\
\hline
\end{tabular}

Table 4. Distribution of patients according to the type of trauma.

\begin{tabular}{ccc}
\hline Type of trauma & Number & \% \\
\hline Abdominal contusion without viscus lesion. & 79 & 35.3 \\
Limbs trauma & 67 & 30 \\
Head injury & 29 & 12.9 \\
Trauma of the pelvic & 15 & 6.7 \\
Maxillo-facial's trauma & 13 & 5.8 \\
Spinal injury & 11 & 4.9 \\
Chest trauma & 5 & 2.2 \\
\hline
\end{tabular}

\subsection{Therapeutic}

\section{- Emergency medical treatment}

The medical treatment was provider in $99.1 \%$ of cases (222/224). It consisted of local skin care, administration of tetanus toxoid and tetanus immunoglobulin according to the vaccination status of the patient, the administration of antibiotics per os or intravenously in open wounds, the administration of antispasmodic orally or intravenously and anticoagulant administration for the prolonged immobilization cases.

\section{- Emergency obstetric treatment}

Manual vacuum aspiration was performed in $1.3 \%$ of patients ( 3 cases). Tocolysis was performed in $3.2 \%$ of patients ( 7 cases) and fetal lung maturation in 3 cases representing $1.3 \%$. 
Caesarean section was performed in 11 patients representing 4.9\% of the sample and 8 patients (3.6\%) delivered vaginally. The vaginal delivery was spontaneous in two cases and in 6 cases it was induced for intra uterine fetal death.

\section{- Orthopedic treatment}

An orthopedic treatment was performed in 9 patients representing 4\%. It was immobilization in 2 cases with plaster, the insertion of Zimmer plate in 2 cases, the usage of a soft neck collar in 1 case, the installation of a mayo clinic in 1 case and a functional treatment in 3 cases due to non-displaced fracture of the obturator's frame with or without of the pubic symphysis involvement.

\section{- Surgical treatment}

Surgical treatment was provided in 15 patients representing 6.7\%. It consisted of a chest tube insertion in a case of rib's fracture with pleural effusion in the right chest; the incision and drainage of large hematoma of the left thigh with repair of perineal tear repair in 1 case; suture for vaginal tear in 3 cases and sutures in the skull, face or limbs in 10 cases.

\subsection{Prognostic Aspects}

All patients benefited an emergency obstetrical ultrasound scan on admission to roll out a placental abruption and was repeated after 48 hours in $93 \%$ of patients. The distribution of obstetric complications according to the term of pregnancy is shown in Table 5.

We noted 4 cases of multiple traumas and 1 case of uterine rupture with hemorrhagic shock. Among the 202 patients which were discharged with live intrauterine gestation, we were able to get in touch with 43 patients, and they were able to carry their pregnancies to term. The outcome was favorable in $97.8 \%$ of cases. No maternal death was recorded.

The average duration of hospital stay was 1.8 days \pm 2.4 days with extremes of 0 and 24 days.

\section{Discussion}

\subsection{Limits}

The retrospective data collection did not allow an exhaustive collection of information on socio-demographic characteristics, the use of security measures and the outcome of pregnancy. Nevertheless, the results obtained have allowed us to lead a discussion.

\subsection{Epidemiology}

\section{- Frequency}

In our study, the frequency of trauma in pregnancy was $0.8 \%$; it is higher than Kouame [5] in Ivory Coast who reported a frequency of $0.02 \%$. But lower than Traore [6] in Mali who reported 1.9\%. The frequency of trauma in pregnancy is steadily increasing. This increase may be related to several factors, including the increasing number of motorcycles and automobile fleet, the non respect of traffic regulations and the low economic status of women in poor countries. These traumas during pregnancy occur mostly among young women [5]-[8].

Table 5. Obstetrical complications according to the term of cyesis.

\begin{tabular}{|c|c|c|c|c|}
\hline Obstetrical consequences & $1^{\text {st }}$ trimester & $2^{\text {nd }}$ trimester & $3^{\text {rd }}$ trimester & Total \\
\hline Preterm labor & & & 10 & 10 \\
\hline Placental abruption & & 4 & & 4 \\
\hline Intra uterine fetal death & & 5 & 3 & 8 \\
\hline Abortion & 3 & 1 & & 4 \\
\hline Threatened abortion & & 2 & & 2 \\
\hline Uterine rupture & & & 1 & 1 \\
\hline Total & 3 & 12 & 14 & 29 \\
\hline
\end{tabular}




\section{- Circumstances of injury}

In our study, the circumstances of the injury were dominated by road traffic accident in $82.6 \%$ of cases; falls in $9.8 \%$ and assaults in $7.6 \%$ of cases. Some authors have reported a predominance of road traffic accidents with frequencies between $49 \%$ and $74.3 \%$ [2] [6] [7]. The high frequency of road traffic accidents in Traore et al. and our series, respectively $74.3 \%$ and $82.6 \%$ could be related to lack of strict implementation of the road traffic regulations. Indeed, motorcycles involved in $99.5 \%$ of accidents are ridded without obtaining the required driving license. In USA, domestic violence is a common cause of trauma during pregnancy. Intimate partner violence ranged from $1 \%-20 \%$ and prevalence of domestic violence in pregnancy is 8307 to 100,000 live births [3] [9].

\subsection{Clinical Pattern and Management}

\section{- Pelvic trauma}

We recorded 13\% of cases of head injuries. Traore et al. and Schiff et al. [6] [10] noted respectively 3.3\% and 1.7\% of head injuries cases. The head injuries observed during road traffic accident are major source of morbidity and require a special management at the intensive care unit.

The injuries have led to pelvic fracture in $1.8 \%$ of cases. This frequency was $6.6 \%$ in the study of Traore et al. [6] and $1.7 \%$ in the Schiff et al. study [10]. In the pelvic fractures, the risk of fetal injury is more important if the presentation is cephalic and fixed. A pelvic fracture is not a definite contraindication for vaginal delivery even in the presence of a slightly displaced pelvic fracture [2] [3].

\section{- Abdominal trauma}

In our study, we recorded $35.3 \%$ of abdominal trauma. Kouame et al. in Ivory Coast, Traore et al. in Mali, Schiff $e$ t al. in the United States of America have reported respectively some frequencies of $14.3 \%, 13.2 \%$ and 4.4\% [5] [6] [10]. Abdominal contusions were mostly observed during road traffic accidents involving motorcycles and during assaults. Their maternal and fetal complications can be multiple and their severity depends mainly on the mechanism of injury. According to some authors the Kleihauer test must be performed in any abdominal trauma during pregnancy.

The Kleihauer test is an essential element for the proper management of all pregnant women who had abdominal trauma to detect a feto-maternal hemorrhage which could be responsible for ischemic and hypoxic fetal disorder and peri ventricular leukomalacia [7].

In our study we found $4 \%$ of cases having placental abruption. Schiff et al. [10] and Traore et al. [6] reported $10.5 \%$ and $6.8 \%$ respectively. The placental abruption is secondary to stretching or damage to the placental disc due to trauma on the gravid uterus. The tocographic recording and ultrasound scan should be repeated regularly during 48 hours following a severe injury because the separations can have slow onset, sometimes taking several days to build up.

The traumas during pregnancy have led to abortion in $1.8 \%$ in our study. The role of stress as a result of shock is discussed in the literature, due to the oxytocin like effects of released catecholamine, but adrenaline level should be much higher than the physiological levels for this contractile action to occur. We noted preterm delivery in 5.4\% of cases in our study. Kouame et al. [6], and Schiff et al. [10] found 28.6\% and 9.5\% of cases having threatened preterm labor respectively. The onset of preterm labor after trauma may be secondary to several factors: premature rupture of membranes, uterine contractions in relation to direct trauma to the uterus, or stress, or anoxia or direct irritation of uterus during laparotomy.

\subsection{Prognosis}

In our study, like that of Kouame [5], we did not notice any maternal death. Traore et al. [6], reported $1.7 \%$ of maternal deaths. The trauma was associated with an initial loss of consciousness in $11.2 \%$ of cases, what predetermine the possible occurrence of secondary complications. Morbidity and mortality in trauma are not negligible. In our study and those of other authors, the fetal prognosis is marked by the occurrence of abortions and intra uterine fetal death, [5] [6] [11]. For Weiss [11], following trauma, fetal mortality is 9 times greater than the maternal mortality and accounts for about $0.5 \%$ of fetal deaths. The trauma was complicated by fetal death in $4.5 \%$ of cases in our study. Our result is higher than Kouame et al. [5] who reported 1.4\%. Missing data in relation to the evolution of pregnancy in our series may explain this difference. Fetal death may be related to placental abruption, massive Feto maternal transfusion, uterine rupture, a fetal trauma, maternal hemorrhagic shock or maternal death. 
To further improve maternal and fetal outcome in our context, a strengthening of road safety measures, medical transport of trauma victims as well an early, appropriate and multidisciplinary managements prove to be essential. Generally the maternal and fetal prognosis has been improved since the introduction of compulsory wearing of seat belts [12].

\section{Conclusion}

Traumas during pregnancy are beyond emergencies within multiple causes and requiring a multidisciplinary management. Seen the limited means of support, establishment of a national strategy to prevent trauma in pregnancy will improve the prognosis for mother and child.

\section{Conflict of Interest}

The authors have no conflicts of interest.

\section{References}

[1] Barerga-Varela, Y., Zietlow, S.P., Bannon, M.P., Harmsen, W.S. and Ilstrup, D.M. (2000) Trauma in Pregnancy. Mayo Clinic Proceedings, 75, 1243-1248. http://dx.doi.org/10.4065/75.12.1243

[2] Mirza, F.G., Devine, P.C. and Gaddipati, S. (2010) Trauma in Pregnancy: A Systematic Approach. American Journal of Perinatology, 27, 579-586. http://dx.doi.org/10.1055/s-0030-1249358

[3] Mendez-Figueroa, H., Dahlke, J.D., Vrees, R.A. and Rouse, D.J. (2013) Trauma in Pregnancy: An Updated Review. American Journal of Obstetrics \& Gynecology, 209, 1-10. http://dx.doi.org/10.1016/j.ajog.2013.01.021

[4] Delotte, J., Behr, M., Thollon, L., Arnoux, P.J., Baque, P., Bongain, A. and Brunet, C. (2007) Femme enceinte et accidentologie routière: Interêt de l'approche numérique. Application à un choc frontal au troisième trimestre de la grossesse avec analyse de l'effet de la ceinture de sécurité. Journal de Gynécologie Obstétrique et Biologie de la Reproduction, 36, 577-581. http://dx.doi.org/10.1016/j.jgyn.2007.03.005

[5] Kouame, K.M., Ouede, R., Anoumou, N.M., Traore, M., Kirioua, B.J. and Varango, G.G. (2009) Traumatismes et Grossesse: Analyse rétrospective d'une courte série de 7 cas au centre hospitalier de Treichville Abidjan (Côte D’ivoire). Médecine d'Afrique Noire, 5606, 30130-30134.

[6] Traore, Y., Traore, M., Mounkoro, N., Teguete, I., Sissoko, A., Diallo, A., Djire, M.Y., Dao, S.Z. and Dolo, A. (2009) Traumatisme et grossesse: Aspects clinique et pronostic à propos de 152 cas colligés au CHU Gabriel Toure. Mali Médical, 24, 18-20.

[7] Barre, I, Winner, N., Caroit, Y. and Boog Phillipe, H. (2006) Traumatisme au cours de la grossesse: Pertinence des éléments de surveillance dans l'évaluation des suites obstétricales. Journal de Gynécologie Obstétrique et Biologie de la Reproduction, 35, 673-677. http://dx.doi.org/10.1016/S0368-2315(06)76462-6

[8] Karadas, S., Gonullu, H., Oncu, M.R., Kurdoglu, Z. and Canbaz, Y. (2012) Pregnancy and Trauma: Analysis of 139 Cases. Journal of the Turkish German Gynecological Association, 13, 118-122. http://dx.doi.org/10.5152/jtgga.2012.13

[9] Bailey, B.A. (2010) Partner Violence during Pregnancy: Prevalence, Effects, Screening, and Management. International Journal of Women's Health, 2, 183-197. http://dx.doi.org/10.2147/IJWH.S8632

[10] Schiff, M.A. and Holt, V.L. (2002) Maternal and Infant Outcomes after Injury During Pregnancy in Washington State from 1989 to 1997. The Journal of Trauma, 53, 939-945. http://dx.doi.org/10.1097/00005373-200211000-00021

[11] Weiss, H.B., Songer, T.J. and Fabio, A. (2001) Fetal Deaths Related to Maternal Injury. Journal of the American Medical Association, 286, 1863-1868. http://dx.doi.org/10.1001/jama.286.15.1863

[12] Romero, V.C. and Pearlman, M. (2012) Maternel Mortality Due to Trauma. Seminars in Perinatology, 36, 60-69. http://dx.doi.org/10.1053/j.semperi.2011.09.012 